\title{
Aneuploidy in human spermatozoa: FISH analysis in men with constitutional chromosomal abnormalities, and in infertile men
}

\author{
Qinghua Shi and Renée H. Martin \\ Department of Medical Genetics, Faculty of Medicine, University of Calgary; and Genetics \\ Department, Alberta Children's Hospital, Calgary, Alberta, T2T 5C7 Canada
}

\begin{abstract}
Reproductive difficulties are associated intimately with cytogenetic abnormalities. This article reviews multicolour fluorescence in situ hybridization studies on spermatozoa from men with constitutional chromosomal abnormalities and the consequences for spermatozoa, and on chromosomal abnormalities in the spermatozoa of infertile men who have normal somatic karyotypes. In 47,XYY men, the frequencies of $24, \mathrm{XY}$ and $24, Y Y$ spermatozoa appear to be $\leqslant 1 \%$. Klinefelter $(47, X X Y)$ and mosaic Klinefelter patients had sperm aneuploidy frequencies of $2-25 \%$ and $1.5-7.0 \%$, respectively. Robertsonian translocation carriers had $3-27 \%$ spermatozoa unbalanced for the chromosomes involved in the translocation, with a possible modest interchromosomal effect, but none of the increased frequencies of chromosomal disomy approached $1 \%$. The frequency of chromosomally unbalanced spermatozoa in reciprocal translocations averages $50 \%$, is strongly dependent on the chromosomes involved in the individual translocation, and may be slightly increased as a result of a small interchromosomal effect. Infertile men with a normal karyotype and low sperm concentration or certain types of morphologically abnormal spermatozoa have a significantly increased risk of producing aneuploid spermatozoa, particularly for the sex chromosomes. An increased risk of sperm aneuploidy was not observed in infertile men with poor sperm motility or in those with a normal karyotype and normal semen parameters.
\end{abstract}

Difficulties with reproduction have been associated with cytogenetic abnormalities since the introduction of human chromosome karyotyping. In recent years, reproductive difficulties have been associated not only with somatic chromosomal abnormalities, but also with cytogenetic abnormalities in the germ cells of infertile individuals with a normal constitutional karyotype. Reproductive difficulties for both types of individuals include an increased risk of pregnancy loss and the birth of children with mental and physical disabilities. Research in this area has become more clinically relevant in the past few years with the advent of intracytoplasmic sperm injection (ICSI). ICSI has been extremely successful for the treatment of male infertility but transmission of cytogenetic defects to offspring is a major concern and in the past few years has been demonstrated to be a reality. Fluorescence in situ hybridization (FISH) analysis involves hybridization of chromosome-specific DNA probes labelled with fluorochromes to complementary DNA sequences on target chromosomes, followed by detection of the bound probes under a fluorescence microscope. FISH analysis of decondensed sperm heads

Email: rhmartin@ucalgary.ca allows the study of thousands of spermatozoa (at present $10^{4}$ spermatozoa per individual per probe are analysed in most laboratories) in a relatively short period. This is especially important for the accurate evaluation of the incidence of aneuploidies in human spermatozoa, because the frequency of disomic spermatozoa for most chromosomes is lower than $0.5 \%$ in normal men (Shi and Martin, 2000a). As well as analysis of adequate numbers of spermatozoa, it is important to use multicolour FISH for reliable results. Two-colour FISH is required for autosomes and three-colour FISH for sex chromosomes to distinguish diploidy (for example, 46, XY with two probes for the sex chromosomes and one probe with two signals for an autosome) from disomy (for example, 24, $X Y$ with two probes for the sex chromosomes and one probe with one signal for an autosome). The effects of donor age and lifestyle factors on the frequency and distribution of chromosomal abnormalities in the spermatozoa of normal men have been reviewed elsewhere (Shi and Martin, 2000a). The present article reviews studies on the consequences of constitutional chromosomal abnormalities observed in spermatozoa and chromosomal abnormalities in the spermatozoa of infertile men who have normal somatic karyotypes. 


\section{Constitutional chromosomal abnormalities}

Studies in infertile men have demonstrated that $2-14 \%$ have constitutional chromosomal abnormalities. The incidence of chromosomal aberrations is dependent on the definition of 'infertility', and is approximately $2 \%$ in males with combined indications of infertility (Meschede et al., 1997), $5 \%$ in oligozoospermic men and $14 \%$ in azoospermic men (Johnson, 1998). These frequencies are all considerably higher than the population incidence of $0.7 \%$ in newborns (Thompson et al., 1986). The most common types of karyotypic abnormality detected include sex chromosomal abnormalities and Robertsonian translocations.

\section{Sex chromosomal abnormalities}

47, XYY. In 1988, 75 sperm karyotypes from a 47,XYY male were studied using the hamster oocyte-human sperm fusion technique and no spermatozoa disomic for the sex chromosomes were found (Benet and Martin, 1988). However, when FISH analysis was performed on the same man, a significantly increased frequency of $X Y$ disomy $(0.6 \%)$ was observed in more than $10^{4}$ spermatozoa studied (Martin et al., 1999). Similar experimental protocols revealed increased frequencies for $24, Y Y$ and $24, X Y$ spermatozoa in more than $10^{4}$ spermatozoa in another 47,XYY man (Shi and Martin, 2000b). Similar FISH studies on $47, X Y Y$ men by other laboratories have demonstrated increased frequencies of spermatozoa with two sex chromosomes ranging from 0.3 (Chevret et al., 1997) to 15\% (Mercier et al., 1996) (for a review, see Shi and Martin, $2000 b)$. These findings indicate that $X Y Y$ cells are able to progress through meiosis and produce $24, Y Y$ or $24, X Y$ spermatozoa (Hultén, 1970; Hultén and Pearson, 1971). The birth of $47, \mathrm{XYY}$ children to $47, \mathrm{XYY}$ males also supports this hypothesis (Boucharlat and Jalbert, 1969; Sundequist and Hellstrom, 1969). However, most children of 47,XYY males are normal and only $1 \%$ or less of $24, Y Y$ and $24, X Y$ spermatozoa were found in 47,XYY men after three-colour FISH (see Shi and Martin, 2000b). These results indicate that the extra $Y$ chromosome is lost during meiosis in most $X Y Y$ cells since the majority of spermatozoa are chromosomally normal.

In theory, it is possible that abnormalities in the segregation of one chromosome affect the segregation of other chromosomes (termed an interchromosomal effect). For example, aneuploidy of the sex chromosomes might affect the segregation of an autosome. Therefore, a number of studies have investigated the normality of other chromosomes as well as the sex chromosomes. Two-colour FISH analysis of spermatozoa from two 47, XYY men did not show a significant increase in the frequency of disomy 21 (Martin et al., 1999; Shi and Martin, 2000b). Similarly, for all six autosomes assessed in nine 47,XYY men, frequencies of disomic spermatozoa did not show any significant difference from concurrent controls, with the exception of one patient who had an increased frequency of chromosome 13 aneuploidy (Shi and Martin, 2000b). Thus, if an interchromosomal effect occurs during meiosis of $47, X Y Y$ males, it would affect specific chromosomes in a minority of men.

$47, X X Y$. Patients with Klinefelter syndrome $(47, X X Y)$ or mosaic variants of Klinefelter syndrome have greatly impaired spermatogenesis, with severe oligozoospermia or azoospermia. Nevertheless, these men are candidates for ICSI, particularly with the new methods used for recovering testicular spermatozoa. Studies on sperm chromosomes from men with Klinefelter syndrome have also demonstrated that the extra sex chromosome appears to be eliminated during spermatogenesis. There have been multicolour FISH studies on spermatozoa from seven men with mosaic Klinefelter syndrome (Table 1). The frequency of sperm aneuploidy in the patients varied from 1.5 (Lim et al., 1999) to $7 \%$ (Kruse et al., 1998), which was significantly higher than in the concurrent controls. There have also been studies of seven men who appear to have a nonmosaic 47, XXY karyotype, with higher sperm aneuploidy frequencies varying from 2 (Rives et al., 2000) to 25\% (Estop et al., 1998a) (Table 1).

There have been several attempts to establish pregnancies using spermatozoa from men with Klinefelter syndrome for ICSI. To date, six normal children have been born (Bourne et al., 1997; Reubinoff et al., 1998; Ron-El et al., 1999, 2000a) and three chromosomally abnormal embryos have been reported: one with $47, \mathrm{XXY}$ at amniocentesis (Ron-El et al., 2000b) and two embryos with chaotic chromosome constitutions, including $\mathrm{XXY}$, discovered by preimplantation genetic diagnosis (Reubinoff et al., 1998).

It appears that men with Klinefelter syndrome who undergo ICSI have a significant risk of producing offspring with sex chromosomal aneuploidies and therefore genetic counselling is appropriate.

\section{Translocations}

Robertsonian translocations. Robertsonian translocations, with a translocated chromosome composed of the long arms of two acrocentric chromosomes, result in balanced Robertsonian translocation carriers with 45 chromosomes. Robertsonian carriers with fusions between chromosomes 13 and 14 are very common among infertile men. When the chromosomes pair during meiosis, the translocated chromosome and its homologues do so as a trivalent. The resulting gametes can be chromosomally normal or aneuploid with an extra or missing chromosome q arm.

Sperm karyotyping studies (using the hamster oocyte system) have demonstrated that the frequency of chromosomally unbalanced spermatozoa is lower than was predicted, with only $3-27 \%$ of spermatozoa unbalanced because of the translocation (Martin, 1995). Three recent $\mathrm{FISH}$ studies have also reported the segregation of two Robertsonian translocations in four men: two with $\mathrm{t}(14 \mathrm{q} ; 21 \mathrm{q})$ (Rousseaux et al., 1995a; Honda et al., 2000) and two with $t(13 q ; 14 q)$ (Escudero et al., 2000). Similar 
Table 1. Summary of normal and disomic sperm frequencies detected by multicolour fluorescence in situ hybridization (FISH) in indivdual patients with Klinefelter syndrome

\begin{tabular}{|c|c|c|c|c|c|c|c|c|c|c|c|}
\hline \multirow[b]{2}{*}{ Karyotype of patients } & \multirow{2}{*}{$\begin{array}{c}\text { Number of } \\
\text { spermatozoa } \\
\text { scored }\end{array}$} & \multicolumn{2}{|c|}{$\begin{array}{c}\text { Normal } \\
\text { spermatozoa (\%) }\end{array}$} & \multicolumn{7}{|c|}{ Disomy frequency (\%) } & \multirow[b]{2}{*}{ Study } \\
\hline & & X-bearing & Y-bearing & 1 & 8 & 12 & 18 & $x X$ & YY & $X Y$ & \\
\hline \multicolumn{12}{|l|}{$47, X X Y$} \\
\hline $47, \mathrm{XXY}$ & 26 & 20.8 & 29.2 & & & & 4.2 & & & 25 & Estop et al., 1998a \\
\hline $47, X X Y$ & 10000 & 51.87 & $24.60^{\mathrm{a}}$ & & & & & 6.92 & 0.21 & $14.58^{\mathrm{a}}$ & Foresta et al., 1998 \\
\hline $47, X X Y$ & 10000 & 56.00 & $28.63^{\mathrm{a}}$ & & & & & 3.34 & 0.09 & $10.03^{\mathrm{a}}$ & Foresta et al., 1998 \\
\hline $47, X X Y$ & 25 & 48.0 & 24.0 & & & & & 0 & 0 & 12 & Foresta et al., 1999 \\
\hline $47, X X Y$ & 20 & 45.0 & 25.0 & & & & & 0 & 0 & 20 & Foresta et al., 1999 \\
\hline $47, X X Y$ & 2206 & $43.43^{b}$ & $48.82^{b}$ & 0.50 & & & & $1.22^{\mathrm{c}}$ & 0.09 & $1.36^{c}$ & $\begin{array}{l}\text { Guttenbach et al., } \\
1997 b\end{array}$ \\
\hline $47, X X Y$ & 10123 & 49.60 & 48.33 & & & $0.42^{d}$ & & $0.45^{d}$ & $0.37^{d}$ & $0.54^{\mathrm{d}}$ & Rives et al., 2000 \\
\hline \multicolumn{12}{|l|}{ Mosaic $47, \mathrm{XXY}$} \\
\hline 46,XY (1.7\%)/47, XXY (98.3\%) & 358 & 50.28 & 44.13 & & & & & 1.12 & 0.56 & 2.23 & $\begin{array}{l}\text { Bielanska et al., } \\
2000\end{array}$ \\
\hline $46, \mathrm{XY}(90 \%) / 47, \mathrm{XXY}(10 \%)$ & 27097 & $52.78^{\mathrm{a}}$ & 43.88 & 0.18 & & & & $0.11^{\mathrm{e}}$ & $0.003^{\mathrm{e}}$ & $2.09 \mathrm{e}$ & $\begin{array}{l}\text { Chevret et al., } \\
1996\end{array}$ \\
\hline \multicolumn{12}{|l|}{$46, \mathrm{XY}(6.1 \%) / 47, \mathrm{XXY}(91.8 \%) /$} \\
\hline $48, \mathrm{XXXY}(2.1 \%)$ & 202 & 50.5 & 42.1 & & & & & 2.0 & 0 & 5.0 & Kruse et al., 1998 \\
\hline $46, X Y(70 \%) / 47, X X Y(30 \%)$ & 1701 & 46.74 & 49.62 & & & & $0.71^{d}$ & $0.29^{f}$ & 0.06 & $0.41^{\mathrm{e}}$ & Lim et al., 1999 \\
\hline $46, X Y(30 \%) / 47, X X Y(70 \%)$ & 3581 & $50.5^{\mathrm{b}}$ & $42.81^{b}$ & & 0.32 & & 0.26 & $0.71^{\mathrm{e}}$ & 0 & $1.3^{\mathrm{e}}$ & Morel et al., 2000 \\
\hline $46, X Y(22 \%) / 47, X X Y(78 \%)$ & 1831 & 47.1 & 44.88 & & 0.20 & & 0.10 & $0.86^{\mathrm{e}}$ & $0.86^{\mathrm{eg}}$ & $1.73^{\mathrm{e}}$ & Morel et al., 2000 \\
\hline $46, X Y(95 \%) / 47, X X Y(5 \%)$ & 20814 & 49.68 & 48.90 & & & $0.49^{d}$ & & $0.24^{\mathrm{e}}$ & 0.20 & $0.62^{d}$ & Rives et al., 2000 \\
\hline
\end{tabular}

a $P<0.05$, Student's $t$ test, compared with concurrent controls; also significantly different from the expected 1:1 for the sex ratio.

b $P<0.01$, significantly different from the expected $1: 1$, chi-squared test.

${ }^{\mathrm{c}} P<0.05,{ }^{\mathrm{d}} P<0.0001,{ }^{\mathrm{e}} P<0.001,{ }^{\mathrm{f}} P<0.01$, compared with concurrent controls; ${ }^{\mathrm{g}} \mathrm{Compared}$ with patient immediately above, chi-squared test.

results were found for the patterns and frequencies of the translocation chromosome segregation, with $11-12 \%$ chromosomally unbalanced spermatozoa for $\mathrm{t}(14 \mathrm{q} ; 21 \mathrm{q})$ and $19-23 \%$ for $\mathrm{t}(13 \mathrm{q} ; 14 \mathrm{q})$. These results corroborate the data from karyotyping analysis of spermatozoa from one $\mathrm{t}(14 \mathrm{q} ; 21 \mathrm{q})$ and three $\mathrm{t}(13 \mathrm{q} ; 14 \mathrm{q})$ carriers, in which most spermatozoa were normal or balanced, and 5-20\% were unbalanced for the chromosomes involved in translocation (Balkan and Martin, 1983; Pellestor et al., 1987; Martin, 1988; Ogawa et al., 2000). Similarly, analysis of cells at meiotic prophase in heterozygous carriers of a Robertsonian translocation showed a predominance of the cisconfiguration of the meiotic trivalent structure hypothesized to lead to alternate segregation and normal or balanced chromosomes (Vidal et al., 1982; Templado et al., 1984).

An interchromosomal effect occurs when the translocated chromosome has an effect on the segregation of chromosomes not involved in the translocation, for example, an increased frequency of trisomy 21 associated with $\mathrm{t}(13 \mathrm{q} ; 14 \mathrm{q})$. No significant interchromosomal effect has been detected in Robertsonian translocation carriers detected by sperm karyotyping (for review, see Guttenbach et al., 1997a). However, because the sample sizes are small (24-149 spermatozoa) when this technique is used, a small interchromosomal effect would be overlooked.

Interchromosomal effects on meiotic segregation of the sex chromosomes in three Robertsonian translocation carriers have been investigated using three-colour FISH (Rousseaux et al., 1995a; Vegetti et al., 2000). Vegetti et al. (2000) found a significant increase in the frequency of $X Y$ disomy in two carriers with $\mathrm{t}(14 ; 21)(\mathrm{q} 10 ; \mathrm{q} 10)$ and $t(13 ; 15)(q 10 ; q 10)$ when compared with concurrent control donors, but Rousseaux et al. (1995a) did not observe a significant increase in the sex chromosome disomy frequency in a $t(14 q ; 21 q)$ carrier.

In addition, interchromosomal effects of a Robertsonian translocation on autosomes have been investigated by multicolour FISH in spermatozoa from four carriers in three studies. Vegetti et al. (2000) reported an increased frequency of disomy 18 and 13 in a $t(14 ; 21)(q 10 ; q 10)$ carrier, and of disomy 18 and 21 in a $t(13 ; 15)(q 10 ; q 10)$ carrier. Rousseaux et al. (1995a) demonstrated an increase in the frequency of disomy 1 in a $t(14 q ; 21 q)$ carrier $(0.67$ versus $0.20 \%, P<0.001)$. Conversely, Blanco et al. (2000) did not detect a significant increase in frequency of disomy 6 or 21 in a $t(13 ; 22)(q 10 ; q 10)$ carrier, when compared with concurrent controls. Thus, these preliminary data from FISH analyses indicate some modest interchromosomal effects, but none of the increased frequencies of chromosomal disomy approached $1 \%$.

In summary, the risk of an unbalanced karyotype resulting from a Robertsonian translocation in spermatozoa is between 3 and $27 \%$, depending on the specific translocation. The final outcome can be a spontaneous 
abortion or a chromosomally abnormal child, depending on the lethality of the chromosome involved. Many of these unbalanced chromosome constitutions are not viable since only $1-2 \%$ of paternally derived Robertsonian translocations are unbalanced at prenatal diagnosis (Boué and Gallano, 1984). Although the risks are low, prospective parents should be informed of them, as the abnormalities can be devastating. In addition, a Robertsonian translocation between two of the same chromosome, for example a $\mathrm{t}(13 \mathrm{q} ; 13 \mathrm{q})$ homozygote, would produce only disomy 13 or nullisomy 13 spermatozoa. ICSI would not be an alternative for such an individual, as all embryos would be trisomy 13 or monosomy 13, with no hope of long-term survival. A case with this particular problem was discovered in the Netherlands after three unsuccessful ICSI attempts (In't Veld et al., 1997) and a male with a $t(13 q ; 13 q)$ has also been observed in the authors' cohort of infertile men contemplating ICSI.

Reciprocal translocations. Reciprocal translocations are an exchange of chromosome material between arms of any two chromosomes, and the risks of chromosomally unbalanced offspring from male carriers are higher than they are for Robertsonian translocations. Sperm karyotyping studies of over 30 reciprocal translocation carriers have demonstrated that $19-77 \%$ of spermatozoa are chromosomally unbalanced, and an average of about 50\% are chromosomally abnormal (Martin and Spriggs, 1995).

During meiosis I, quadrivalents are formed between translocated chromosomes and their normal homologues in reciprocal translocation carriers. In alternate segregation, the translocated chromosomes segregate to one pole and the normal homologues to the other, producing balanced and normal gametes, respectively. Chromosomally unbalanced gametes are produced in adjacent 1 and adjacent 2 segregations (in which homologous centromeres move to opposite poles and the same poles, respectively) and in 3:1 segregation. FISH analysis of interphase spermatozoa using two centromeric probes specific to the involved chromosomes does not allow differentiation of alternate and adjacent 1 segregants; the large number of spermatozoa analysed allows detection of the rarer adjacent 2 and 3:1 segregations. However, it is possible, using centromeric probes combined with locus-specific probes, to detect all types of segregations using FISH analysis. In comparison with the labour-intensive and time-consuming sperm karotyping analysis, FISH analysis of decondensed sperm heads allows the analysis of very large numbers of spermatozoa.

A total of 159920 spermatozoa from 19 reciprocal translocation carriers has been analysed using the multicolour FISH technique for the segregation of the chromosomes involved in translocations (Table 2). The segregation pattern for an affected chromosome is dependent upon the chromosome involved. The frequencies for each type of segregation are very similar between individuals carrying translocations involving the same chromosomes, for example, two donors with $\mathrm{t}(3 ; 9)$ (Honda et al., 1999), two $\mathrm{t}(6 ; 11)$ donors (Rousseaux et al., 1995b) and two $\mathrm{t}(11 ; 22)$ donors (Estop et al., 1999; Van Assche et al., 1999). Conversely, among pairs of donors in which one of the translocated chromosomes is the same and the other is in the same chromosome group, for example, in $\mathrm{t}(1 ; 10)$ versus $t(1 ; 11), t(5 ; 7)$ versus $t(5 ; 8), t(7 ; 8)$ versus $t(7 ; 9)$, and $t(7 ; 9)$ versus $\mathrm{t}(8 ; 9)$, the segregation patterns are very different. These results corroborate earlier observations from sperm karyotyping that the risk of producing chromosomally unbalanced gametes depends greatly on the chromosomes involved in the individual translocation (for a review, see Guttenbach et al., 1997a).

In most reciprocal translocation carriers, alternate segregants are the most common, occurring at approximately 44-51\%; adjacent 1 segregants have a frequency of 16-40\%; adjacent 2 segregants are less common with a mean frequency of $9 \%$ (range $3-16 \%$ ); and 3:1 segregants occur at a mean frequency of $11 \%$ with a wide range of $2-40 \%$ (Table 2). These results are in agreement with those from sperm karyotyping analysis (Martin and Spriggs, 1995; Guttenbach et al., 1997a), although it has been suggested that under certain conditions, this typical segregation pattern does not occur. Jalbert et al. (1980) postulated that in the presence of a quadrivalent with unequal sizes of translocated segments and with the participation of an acrocentric chromosome, a 3:1 segregation would preferentially occur. The common $t(11 ; 22)(q 23 ; q 11)$ has a higher proportion of 3:1 segregants among chromosomally unbalanced children. However, in an early study of sperm karyotyping, a $t(11 ; 22)$ heterozygote was shown to have approximately equal frequencies of adjacent 1 , adjacent 2 and 3:1 segregations, indicating that the other segregants are formed but do not survive embryonic development (Martin, 1984). Similarly, a recent study of a $t(11 ; 22)$ male by electron microscope analysis of the synaptonemal complexes and dual-colour FISH in metaphase I and II did not demonstrate a preferential 3:1 segregation, again indicating post-zygotic selection as the reason for the predominance of 3:1 segregants at birth (Armstrong et al., 2000). Two other FISH studies (Estop et al., 1999; Van Assche et al., 1999) have shown more frequent 3:1 segregation in spermatozoa but, as pointed out by Armstrong et al. (2000), the majority of these spermatozoa were monosomic with only $5-7 \%$ carrying the extra chromosome that would be consistent with no preference toward a 3:1 segregation.

A total of 323931 spermatozoa from 29 reciprocal translocation carriers has been analysed for an interchromosomal effect of the translocation on uninvolved chromosomes using the multicolour FISH approach (Table 3). Comparisons of disomic spermatozoa frequencies for chromosomes not involved in translocations between each translocation carrier and the concurrent controls were carried out using a $2 \times 2$ chi-squared test. An increased frequency was observed for at least one type of disomy in $58 \%$ of carriers (17/29), while a decreased sex chromosome 
Table 2. Segregation of chromosomes in spermatozoa from reciprocal translocation heterozygotes studied by multicolour fluorescence in situ hybridization (FISH) or primed in situ (PRINS)

\begin{tabular}{|c|c|c|c|c|c|c|c|c|}
\hline \multirow[b]{2}{*}{ Translocation } & \multirow{2}{*}{$\begin{array}{l}\text { Number of } \\
\text { cells scored }\end{array}$} & \multicolumn{6}{|c|}{ Segregation pattern (\%) } & \multirow[b]{2}{*}{ Reference } \\
\hline & & Normal & Balanced & Adjacent 1 & Adjacent 2 & $3: 1$ & $4: 0$ & \\
\hline$t(1 ; 10)(p 22.1 ; q 22.3)$ & 4036 & $90.5^{\mathrm{a}}$ & & & 4.9 & 3.9 & - & Van Hummelen et al., 1997 \\
\hline$t(1 ; 11)(p 36.3 ; q 13.1)$ & 13071 & $82.5^{\mathrm{a}}$ & & & 8.3 & 9.2 & & Spriggs and Martin, 1994 \\
\hline $\mathrm{t}(2 ; 14)(\mathrm{p} 23.1 ; \mathrm{q} 31)$ & 4610 & $88^{a}$ & & & 5.5 & 6.5 & - & Rousseaux et al., 1995b \\
\hline $\mathrm{t}(2 ; 18)(\mathrm{p} 21 ; q 11.2)$ & 3139 & $45^{\mathrm{b}}$ & & 30.8 & 10.9 & 13.2 & 0 & Estop et al., 1998b \\
\hline $\mathrm{t}(3 ; 9)(\mathrm{q} 26.2 ; \mathrm{q} 32)$ & 10022 & $88.4^{\mathrm{a}}$ & & & 5.4 & 5.9 & & Honda et al., 1999 \\
\hline$t(3 ; 9)(q 25 ; q 32)$ & 10278 & $89.2^{\mathrm{a}}$ & & & 6.0 & 4.5 & & Honda et al., 1999 \\
\hline$t(3 ; 11)(q 27.3 ; q 24.3)$ & 4029 & $44.3^{b}$ & & 15.9 & 6.6 & 28.9 & 0.8 & Martini et al., 1998 \\
\hline $\mathrm{t}(5 ; 7)(\mathrm{q} 21 ; \mathrm{q} 32)$ & 296 & 28 & 21.6 & 32.5 & 16.2 & 1.7 & - & Cifuentes et al., 1999 \\
\hline$t(5 ; 8)(q 33 ; q 13)$ & 10344 & $46.5^{b}$ & & 39.5 & 7.2 & 6.8 & - & Blanco et al., 1998 \\
\hline $\mathrm{t}(6 ; 11)(\mathrm{q} 14 ; \mathrm{p} 14)$ & 13968 & $86^{\mathrm{a}}$ & & & 10.5 & 3.5 & 0.1 & Rousseaux et al., 1995b \\
\hline $\mathrm{t}(6 ; 11)(\mathrm{q} 14 ; \mathrm{p} 14)$ & 13876 & $87.4^{\mathrm{a}}$ & & & 9.0 & 3.1 & 0.5 & Rousseaux et al., 1995b \\
\hline $\mathrm{t}(7 ; 8)(\mathrm{q} 11.21 ; \mathrm{cen})$ & 34527 & 30.4 & 26.3 & 25.1 & 11.1 & 7.1 & & Mercier et al., 1998 \\
\hline $\mathrm{t}(7 ; 9)(\mathrm{q} 33 ; \mathrm{p} 21)^{\mathrm{c}}$ & 10658 & $86^{\mathrm{a}}$ & & & 10.4 & 3 & $\sim 0.5$ & Pellestor et al., 1997 \\
\hline $\mathrm{t}(7 ; 18)(\mathrm{q} 35 ; \mathrm{q} 11)^{\mathrm{c}}$ & 10462 & $77.2^{\mathrm{a}}$ & & & 15.9 & 6.6 & $\sim 0.4$ & Pellestor et al., 1997 \\
\hline $\mathrm{t}(8 ; 9)(\mathrm{q} 24.2 ; \mathrm{q} 32)$ & 3118 & $45.4^{\mathrm{b}}$ & & 41.9 & 3.17 & 9.6 & 0 & Estop et al., 1998b \\
\hline $\mathrm{t}(10 ; 12)(\mathrm{q} 26.1 ; \mathrm{p} 13.3)$ & 10049 & $84.3^{\mathrm{a}}$ & & & 11 & 4.4 & & Estop et al., 1997 \\
\hline $\mathrm{t}(11 ; 22)(\mathrm{q} 23 ; \mathrm{q} 11)$ & 1925 & $27.4^{b}$ & & 17.6 & 12.5 & 40.1 & - & Estop et al., 1999 \\
\hline$t(11 ; 22)(q 25 ; q 22)$ & 1012 & $29.1^{b}$ & & 21.2 & 15.2 & 34.6 & & Van Assche et al., 1999 \\
\hline $\mathrm{t}(\mathrm{Y} ; 16)(\mathrm{q} 11.21 ; \mathrm{q} 24)$ & 500 & $51^{\mathrm{b}}$ & & 36 & & 12 & & Giltay et al., 1999 \\
\hline Mean & 8417 & 38.6 & 24 & 28.9 & 9.4 & 10.8 & 0.3 & \\
\hline
\end{tabular}

aAlternate and adjacent 1 segregants cannot be differentiated.

bNormal and balanced segregants cannot be differentiated.

cPRINS labelling technique. All other studies were FISH.

disomy was reported in 3\% of carriers (1/29) (Cifuentes et al., 1999). In the remaining 11 of 29 carriers $(38 \%)$, the frequencies of disomy investigated were in the control range (Table 3). No interchromosomal effect has been observed in sperm karyotyping analyses of 4445 spermatozoa from 36 reciprocal translocation carriers (for a review, see Guttenbach et al., 1997a). However, the smaller number of spermatozoa analysed per donor probably accounts for the failure to detect increased hyperhaploidy frequency by karyotype analysis.

The presence of an interchromosomal effect and the increase in the disomy frequency when there is an interchromosomal effect, varied greatly among the chromosomes studied. For example, an interchromosomal effect with an increased disomy frequency of 1.5-2.5 times that of concurrent controls was observed for chromosome 1 in all of three carriers analysed. An interchromosomal effect for chromosome 21 was observed in 9 of 22 carriers (41\%), with disomy frequencies 1.4-6.6 times those of control donors. Sex chromosome disomy in 8 of 29 (28\%) carriers was 1.7-6.0 times greater than that seen in controls, and no interchromosomal effect at all was detected for chromosomes $6,12,15$ and 17 . These results indicate that during meiosis, segregation of certain chromosomes such as chromosomes 1 and 21 are more frequently affected by the presence of a translocation. Studies of the interchromosomal effect on more chromosomes in reciprocal translocation carriers are needed to confirm or refute these findings.

Both sperm karyotype and FISH data indicate that the frequency of chromosomally unbalanced spermatozoa from reciprocal translocation heterozygotes is, on average, 50\% with possibly a small additional risk owing to an interchromosomal effect. Many of these imbalances are not compatible with survival, and the average frequency of paternally derived translocation imbalances at prenatal diagnosis is $12 \%$ (Boué and Gallano, 1984) (the same frequency as maternally derived translocation imbalances). However, some translocations have higher risks of imbalance and survival, and all surviving fetuses have serious consequences including mental and physical disabilities. A number of fetuses with unbalanced segregations of reciprocal translocations have been reported after ICSI (Meschede et al., 1997; Belin et al., 1999). These significant risks indicate that chromosome karyotyping is important for all men contemplating ICSI, and this should be followed by genetic counselling if an abnormality is discovered. 


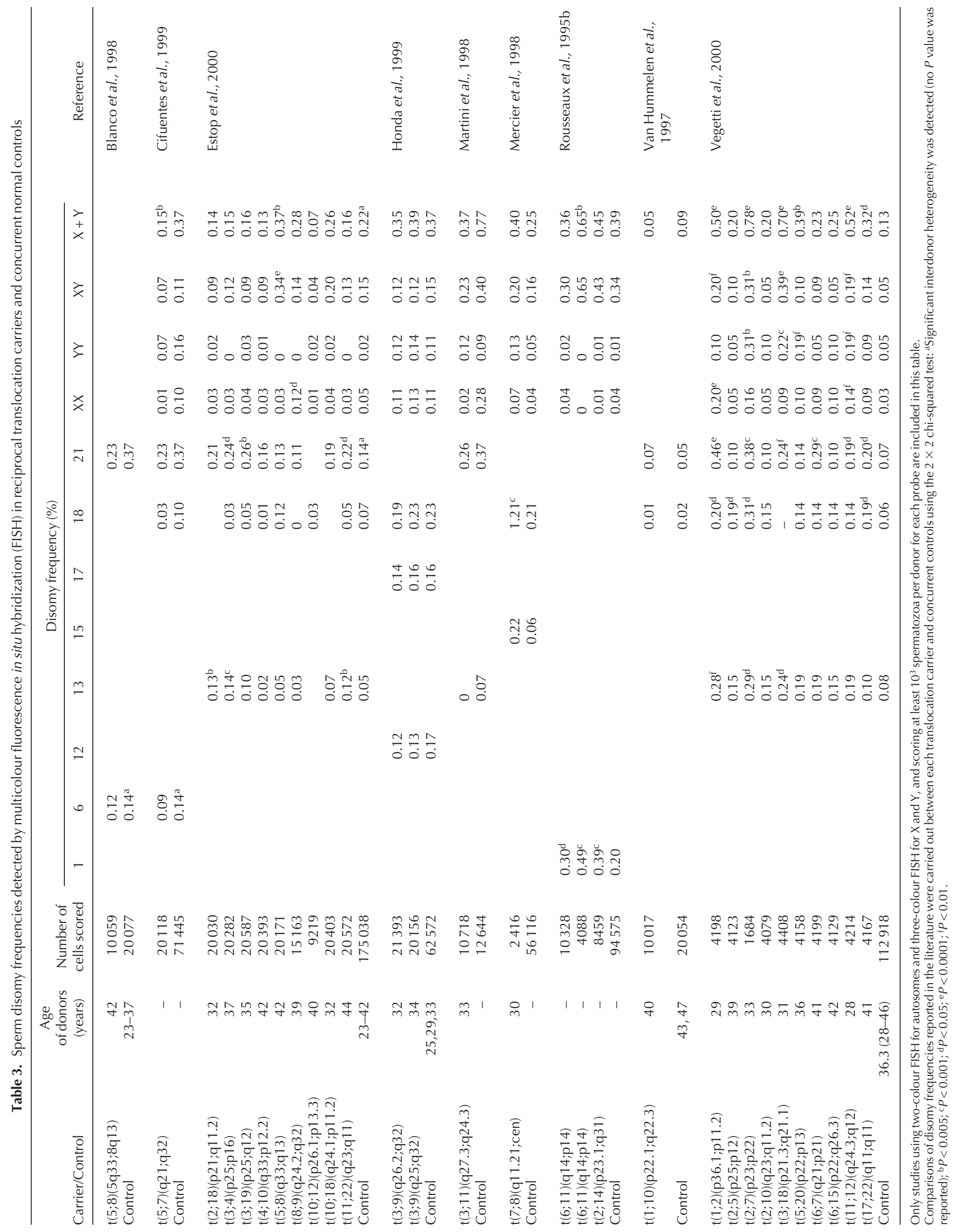




\section{Infertile men with normal karyotypes}

Sperm chromosome complements in infertile men with normal 46,XY karyotypes have been studied to determine whether meiosis in these men is prone to errors of nondisjunction, leading to aneuploidy. More than 20 sperm FISH studies from 364 patients have reported chromosome disomy frequencies (Table 4).

\section{Infertile men with abnormal semen parameters}

Five men with oligo-, aestheno- or teratozoospermia and a normal somatic 46, XY karyotype were studied by both sperm chromosome and FISH analysis (Moosani et al., 1995). Approximately 100 sperm karyotypes were analysed for each infertile patient. The results demonstrated a significant increase in the frequency of total sperm chromosome abnormalities in infertile patients compared with control donors. For each patient, multi-colour FISH analysis was performed on a minimum of $10^{4}$ sperm nuclei per chromosome probe for chromosomes 1, 12, $\mathrm{X}$ and $\mathrm{Y}$. There was a significant increase in the frequency of disomy for chromosome 1, and particularly for $X Y$ disomy, in infertile patients. This study was expanded to analyse sperm chromosomal abnormalities in additional infertile men by $\mathrm{FISH}$ analysis, and the original results were corroborated with significantly increased frequencies of disomy for chromosome 1 and XY disomy (Martin, 1996). If a spermatozoon with disomy 1 fertilized a normal oocyte, a trisomy 1 embryo would be produced, which would probably be lost before implantation because of the lethality of this condition. However, a 24,XY spermatozoon would produce a 47,XXY embryo with Klinefelter syndrome, which has a high probability of surviving to term.

Along with the sex chromosomes, aneuploidies for chromosomes 13 and 21 are clinically significant because these trisomies can sometimes survive to term (resulting in Patau syndrome and Down syndrome, respectively). The same infertile men were studied to determine whether they have an increased risk of aneuploidy for chromosomes 13 and 21 in their spermatozoa. More than $9 \times 10^{4}$ spermatozoa were studied by FISH analysis, and there was a statistically significant increase in the frequency of disomy for both chromosomes 13 and 21, although not as marked an increase as that for the sex chromosomes (Mclnnes et al., 1998). Similar results were obtained and extended to other chromosomes by most other studies using two- or threecolour FISH analysis. For example, Pang et al. (1999) detected a higher incidence of disomy in 10 oligoaesthenoteratozoospermia (OAT) patients for autosomes 4, 6, $7,8,9,10,11,12,13,17,18$ and 21 and for the sex chromosomes than in fertile donors, and the frequency of sex chromosome disomy increased the most markedly. Aran et al. (1999) and Nishikawa et al. (2000) found a significantly increased $X Y$ disomy frequency in OAT patients. In addition, a significantly increased disomy frequency for chromosomes 13, 21, $\mathrm{X}$ and $\mathrm{Y}$ in OAT patients was observed by Pfeffer et al. (1999), Ushijima et al. (2000) and Vegetti et al. (2000). These results clearly indicate that infertile men with abnormal semen parameters have an increased risk of aneuploid spermatozoa, particularly for the sex chromosomes. Reports based on prenatal diagnosis in ICSI pregnancies have indicated an increased risk of sex chromosomal abnormalities in approximately $1 \%$ of cases (Liebaers et al., 1995), and these abnormalities have been shown to be of paternal origin (Van Opstal et al., 1997). One of the men in our original study had a very high frequency of $\mathrm{XY}$ disomy in his spermatozoa, 14-fold higher than in controls. He subsequently underwent ICSI and produced a 47,XXY fetus (Moosani et al., 1999). Thus, the frequency of abnormalities in spermatozoa may predict a real risk of abnormal offspring.

These first studies of sperm chromosomal abnormalities in infertile men have tended to group all types of infertility together. The next avenue of study will be to separate out various types of infertility and determine which subsets are associated with an increased risk. Some studies have started to address this question.

Disomy frequency and sperm morphology. Studies carried out to investigate the correlation between chromosome aneuploidy and morphologically abnormal spermatozoa by FISH have produced no consistent results (Table 4). No statistical correlations between the frequency of disomy for all the chromosomes analysed and sperm morphology were found in two studies (Rives et al., 1999; Vegetti et al., 2000) of 50 and 19 infertile men, respectively. These results are in agreement with the data obtained by sperm karyotyping using the human spermatozoa-hamster egg fusion technique (Martin and Rademaker, 1988), and after sperm injection into mouse oocytes (Lee et al., 1996). In addition, Carrell et al. (1999) reported the frequencies of disomy for chromosomes 13, 18, 21, $\mathrm{X}$ and $\mathrm{Y}$ in two siblings with round-headed sperm syndrome and similar semen parameters. Compared with healthy controls, sibling 1 had significantly increased disomy for chromosomes 13, 21 and the sex chromosomes, while sibling 2 with the exception of disomy 21 did not. However, Ushijima et al. (2000) reported that the incidence of sex chromosome abnormalities increased significantly with an increase in the percentage of morphologically abnormal spermatozoa in eight OAT patients. Bernardini et al. (1998) indicated that regardless of the type of semen analysed, a high percentage of certain types of morphologically abnormal spermatozoa (that is, macrocephalic, and one head with two tails) were found to be disomic in 13 infertile men including seven cases with normal semen parameters. Thus, there is conflicting evidence for a relationship between sperm morphology and the frequency of sperm aneuploidy. It is possible that only certain types of morphologically abnormal spermatozoa are associated with an increased frequency of aneuploidy.

Disomy frequency and sperm motility. In contrast to the contradictory results of studies on the relationship between 


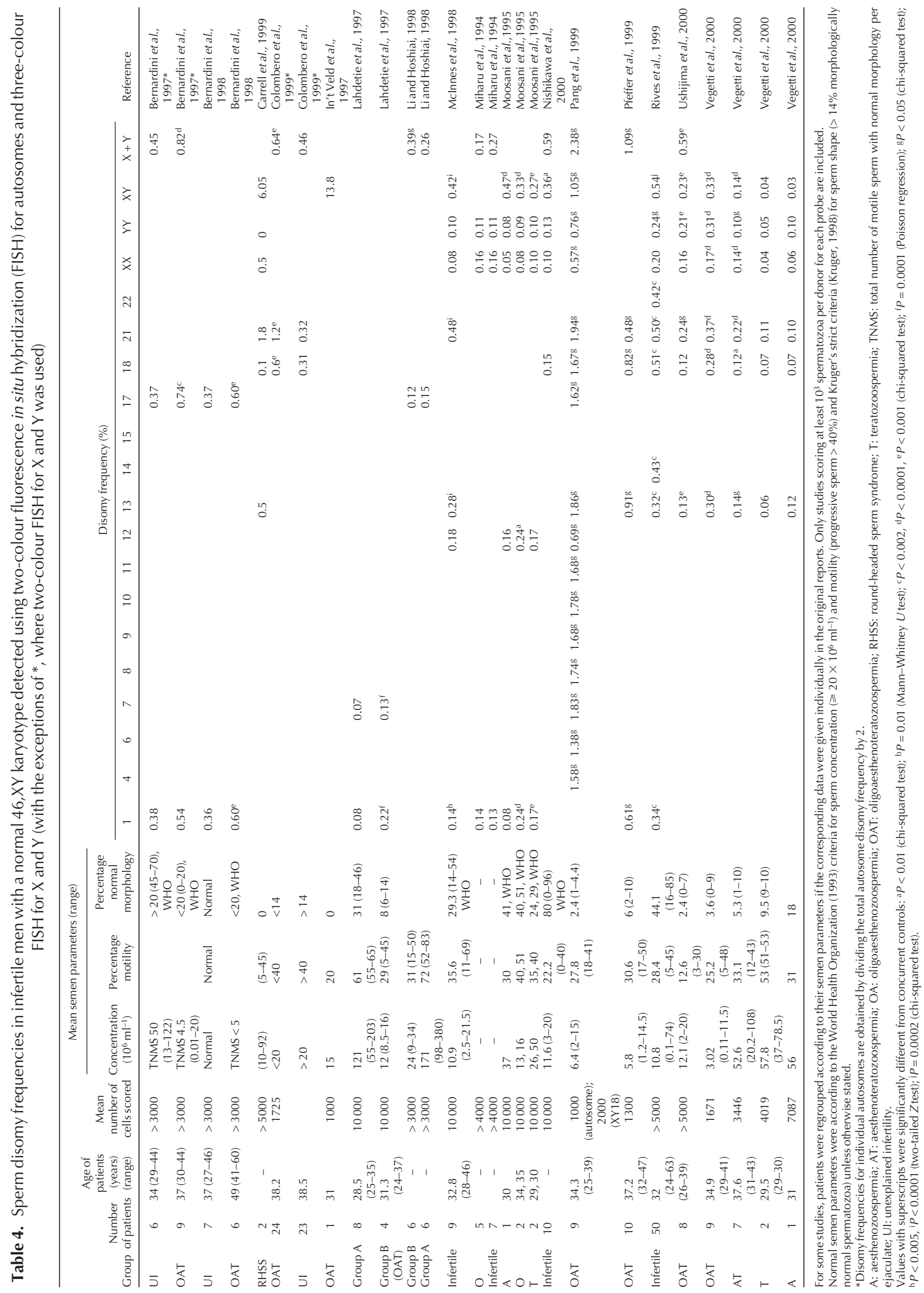


disomy frequency and sperm morphology, most studies comparing disomy frequency and sperm motility showed very consistent results. Six out of seven studies (86\%) did not find any significant association between disomy frequency and sperm motility. Rives et al. (1999) reported no correlation between total disomy frequency for the chromosomes analysed and global sperm motility in 50 infertile patients. Aran et al. (1999) did not find a significant increase in the frequency of disomy for chromosomes $18, \mathrm{X}$ and $Y$ in five aesthenozoospermic patients. Moreover, normal men and infertile patients with or without normal semen parameters showed no significant differences in the frequency of disomy between unselected spermatozoa and motile spermatozoa selected by the swim-up method (Martinez-Pasarell et al., 1997), between morphologically normal, immotile but viable spermatozoa and normal motile spermatozoa (Zeyneloglu et al., 2000), or between spermatozoa in swim-up motile fractions and in the pellet (Pfeffer et al., 1999; Dyk et al., 2000). The only exception was a study by Li and Hoshiai (1998), in which abnormal semen had a significantly higher frequency of disomy for the sex chromosomes in unselected spermatozoa than in spermatozoa selected by the swim-up method.

Disomy frequency and sperm concentration. The association between sperm concentration and sperm aneuploidy has probably been the most extensively studied (Table 4). Finkelstein et al. (1998) found significantly higher frequencies of spermatozoa disomic for all the chromosomes analysed in 12 men with a sperm concentration $\leqslant 30 \times 10^{6} \mathrm{ml}^{-1}$ than in eight donors with a sperm concentration $>60 \times 10^{6} \mathrm{ml}^{-1}$. Rives et al. (1999) reported that the mean frequency of disomy for autosomes $1,13,14$, 18,21 and $22(P<0.001)$ and gonosomes $(P=0.002)$ in 50 infertile men increased significantly as sperm concentration decreased. Such a correlation has been confirmed by Vegetti et al. (2000) in a study of chromosomes 13, 18, 21, X and $Y$ in 15 infertile men. Nishikawa et al. (2000) observed a significantly increased frequency of $X Y$ disomy in eight of ten OAT patients, and in all of five men with a sperm concentration $<13 \times 10^{6} \mathrm{ml}^{-1}$. Aran et al. (1999) found a significantly higher frequency of $X Y$ disomy in 14 OAT patients when compared with normal donors. Overall, in patients with low sperm concentrations, a significantly increased frequency of disomy for chromosome 21 and the sex chromosomes, particularly XY disomy, was found consistently by most groups (Table 4).

It has been argued that a generalized pairing abnormality in the meiotic chromosomes may predispose to both oligozoospermia and nondisjunction (Martin, 1996). Oligozoospermia has been associated with pairing problems in both autosomes and gonosomes. Egozcue et al. (1983) indicated that there is an increased frequency of pairing disruptions resulting in meiotic arrest in infertile men. Martin (1996) hypothesized that it is possible that a pairing abnormality in these infertile men leads to meiotic arrest in some cells, resulting in oligozoospermia, and nondisjunction in other cells capable of completing spermatogenesis, resulting in aneuploid spermatozoa. As sex chromosomes and small chromosomes (which generally have a single crossover) are particularly susceptible to pairing abnormalities, if recombination is absent or reduced, nondisjunction could result. Hassold et al. (1991) have determined that 47,XXY of paternal origin is associated with a reduced recombination frequency. Shi et al. (2001) have demonstrated by single sperm PCR that XY spermatozoa have a reduced frequency of recombination in the pseudoautosomal region compared with normal X or Y spermatozoa. Savage et al. (1998) have observed altered recombination in cases of trisomy 21 of paternal origin. Thus, it is plausible that infertile men have decreased recombination and pairing, leading to both meiotic arrest (oligozoospermia) and nondisjunction (disomic spermatozoa).

In summary, our studies and those of others have demonstrated an increased frequency of sex chromosomal aneuploidy in the spermatozoa of infertile men (particularly oligozoospermia and OAT patients). The relative risk of sex chromosome aneuploidy is 2-3 times that in control donors, which is in agreement with the frequency of $1 \%$ sex chromosomal abnormalities observed from prenatal diagnoses after ICSI. Recent data for chromosomes 13 and 21, also clinically significant trisomies, show more modest relative risks. However, the most recent surveys of ICSI results demonstrate an increased frequency of autosomal aberrations, as well as sex chromosomal abnormalities in ICSI children compared with the general neonatal population (Bonduelle et al., 1998).

\section{Infertile men with normal semen parameters}

There have been several studies of infertile men with normal semen parameters (Table 4). Bernardini et al. (1997, 1998) did not find a significant increase in the frequency of disomy for autosomes and gonosomes, when compared with normal donors. These results are consistent with an earlier observation by Miharu et al. (1994) in seven patients with normal semen parameters and confirmed by Lahdetie et al. (1997). Thus, preliminary studies indicate that there is no increased risk of sperm aneuploidy in infertile patients with normal semen parameters (Table 4).

\section{Testicular spermatozoa}

New developments in infertility treatment include surgical retrieval of spermatozoa from testicular tissue for ICSI when there are no spermatozoa in the ejaculate. These testicular spermatozoa may have very different risks for aneuploidy from those of ejaculated spermatozoa. Aneuploidy frequencies for chromosomes 13, 21, X and $Y$ have been studied using FISH analysis in testicular spermatozoa extracted from three $46, \mathrm{XY}$ men with nonobstructive azoospermia (Martin et al., 2000). The infertile patients had an increased frequency of disomy for chromosomes 13, 21 and $X Y$ disomy compared with controls, but none of these increases reached statistical 
significance. There were no significant differences in the sex ratio or the frequency of diploidy in azoospermic patients compared with normal control donors. This first report on chromosomal aneuploidy in spermatozoa extracted from testes of patients with non-obstructive azoospermia indicates that some azoospermic men do not have a substantially increased risk of chromosomally abnormal spermatozoa. However, this study was based on only 3324 spermatozoa since testicular spermatozoa are available only in small numbers. Zech et al. (2000) reported congenital malformations in two out of four pregnancies initiated by intracytoplasmic injection of spermatids; one of the fetuses had trisomy 9. Further studies on other patients are urgently required.

The authors would like to give special thanks to Evelyn Ko for proofreading the manuscript. This research was supported by a grant from the Medical Research Council of Canada to R. H. Martin.

\section{References}

Key references are identified by asterisks.

Aran B, Blanco J, Vidal F, Vendrell JM, Egozcue S, Barri PN, Egozcue J and Veiga A (1999) Screening for abnormalities of chromosomes $X, Y$, and 18 and for diploidy in spermatozoa from infertile men participating in an in vitro fertilization-intracytoplasmic sperm injection program Fertility and Sterility $\mathbf{7 2}$ 696-701

Armstrong SJ, Goldman AS, Speed RM and Hultén MA (2000) Meiotic studies of a human male carrier of the common translocation, $\mathrm{t}(11 ; 22)$ suggests postzygotic selection rather than preferential 3:1 MI segregation as the cause of liveborn offspring with an unbalanced translocation American Journal of Human Genetics 67 601-609

Balkan W and Martin RH (1983) Chromosome segregation into the spermatozoa of two men heterozygous for different reciprocal translocations Human Genetics 63 345-348

Belin V, Farhat M and Monset-Couchard M (1999) Intracytoplasmic sperm injection pregnancy with trisomy 20p and monosomy $22 q$ in a newborn resulting from a balanced paternal translocation Biology of the Neonate 75 398-401

Benet J and Martin R (1988) Sperm chromosome complements in a 47,XYY male Human Genetics 78 313-315

Bernardini L, Martini E, Geraedts JP, Hopman AH, Lanteri S, Conte N and Capitanio GL (1997) Comparison of gonosomal aneuploidy in spermatozoa of normal fertile men and those with severe male factor detected by in situ hybridization Molecular Human Reproduction 3 431-438

Bernardini L, Borini A, Preti S, Conte N, Flamigni C, Capitanio GL and Venturini PL (1998) Study of aneuploidy in normal and abnormal germ cells from semen of fertile and infertile men Human Reproduction 13 3406-3413

Bielanska M, Tan SL and Ao A (2000) Fluorescence in situ hybridization of sex chromosomes in spermatozoa and spare preimplantation embryos of a Klinefelter 46,XY/47,XXY male Human Reproduction 15 440-444

Blanco J, Egozcue J, Clusellas N and Vidal F (1998) FISH on sperm heads allows the analysis of chromosome segregation and interchromosomal effects in carriers of structural rearrangements: results in a translocation carrier, t(5;8)(q33;q13) Cytogenetics and Cell Genetics 83 275-280

Blanco J, Egozque J and Vidal F (2000) Interchromosomal effects for chromosome 21 in carriers of structural chromosome reorganizations determined by flourescence in situ hybridization on sperm nuclei Human Genetics 106 500-505

Bonduelle M, Aytoz A, Van Assche E, Devroey P, Liebaers I and Van Steirteghem A (1998) Incidence of chromosomal aberrations in children born after assisted reproduction through intracytoplasmic sperm injections Human Reproduction 13 781-782
Boucharlat J and Jalbert P (1969) On XYY chromosome triplet. Its importance in psychiatry. Apropos of a case Annales MedicoPsychologiques 1 793-797

Boué H and Gallano P (1984) A collaborative study of the segregation of inherited chromosome structural rearrangements in 1356 prenatal diagnoses Prenatal Diagnosis 4 45-67

Bourne H, Stern K, Clarke G, Pertile M, Speirs A and Baker HW (1997) Delivery of normal twins following the intracytoplasmic injection of spermatozoa from a patient with 47,XXY Klinefelter's syndrome Human Reproduction 12 2447-2450

Carrell D, Emery BR and Liu L (1999) Characterization of aneuploidy rates, protamine levels, ultrastructure, and functional ability of round-headed sperm from two siblings and implications for intracytoplasmic sperm injection Fertility and Sterility 71 511-516

Chevret E, Rousseaux S, Monteil M, Usson Y, Cozzi J, Pelletier R and Sele B (1996) Increased incidence of hyperhaploid 24,XY spermatozoa detected by three-colour FISH in a 46, XY/47, XXY male Human Genetics 97 171-175

Chevret E, Rousseaux S, Monteil M, Usson Y, Cozzi J, Pelletier R and Sele B (1997) Meiotic behaviour of sex chromosomes investigated by threecolour FISH on 35142 sperm nuclei from two 47, XYY males Human Genetics 99 407-412

Cifuentes P, Navarro J, Blanco J, Vidal F, Miguez L, Egozcue J and Benet J (1999) Cytogenetic analysis of sperm chromosomes and sperm nuclei in a male heterozygous for a reciprocal translocation $\mathrm{t}(5 ; 7)(\mathrm{q} 21 ; \mathrm{q} 32)$ by in situ hybridization European Journal of Human Genetics 7 231-238

Colombero LT, Hariprashad JJ, Tsai MC, Rosenwaks Z and Palermo GD (1999) Incidence of sperm aneuploidy in relation to semen characteristics and assisted reproductive outcome Fertility and Sterility 72 90-96

Dyk QV, Lanzendorf S, Kolm P, Hodgen GD and Mahony MC (2000) Incidence of aneuploid spermatozoa from subfertile men: selected with motility versus hemizona-bound Human Reproduction 15 1529-1536

Egozcue J, Templado C, Vidal F, Navarro J, Morer-Fargas F and Marina S (1983) Meiotic studies in a series of 1100 infertile and sterile males Human Genetics 65 185-188

Escudero T, Lee M, Carrel D, Blanco J and Munne S (2000) Analysis of chromosome abnormalities in sperm and embryos from two 45,XY,t(13;14)(q10;q10) carriers Prenatal Diagnosis 20 599-602

Estop AM, Cieply KM and Aston CE (1997) The meiotic segregation pattern of a reciprocal translocation $\mathrm{t}(10 ; 12)(\mathrm{q} 26.1 ; \mathrm{p} 13.3)$ by fluorescence in situ hybridization sperm analysis European Journal of Human Genetics $578-82$

Estop AM, Munne S, Cieply KM, Vandermark KK, Lamb AN and Fisch H (1998a) Meiotic products of a Klinefelter 47,XXY male as determined by sperm fluorescence in situ hybridization analysis Human Reproduction 13 124-127

Estop AM, Cieply KM, Wakim A and Feingold E (1998b) Meiotic products of two reciprocal translocations studied by multicolor fluorescence in situ hybridization Cytogenetics and Cell Genetics 83 193-198

Estop AM, Cieply KM, Munne S and Feingold E (1999) Multicolor fluorescence in situ hybridization analysis of the spermatozoa of a male heterozygous for a reciprocal translocation $\mathrm{t}(11 ; 22)(\mathrm{q} 23 ; \mathrm{q} 11)$ Human Genetics 104 412-417

Estop A, Cieply K, Munne S, Surt U, Wakim A and Feingold E (2000) Is there an interchromosomal effect in reciprocal translocation carriers? Sperm FISH studies Human Genetics 106 517-524

Finkelstein S, Mukamel E, Yavetz H, Paz G and Avivi L (1998) Increased rate of nondisjunction in sex cells derived from low-quality semen Human Genetics 102 129-137

Foresta C, Galeazzi C, Bettella A, Stella M and Scandellari C (1998) High incidence of sperm sex chromosomes aneuploidies in two patients with Klinefelter's syndrome Journal of Clinical Endocrinology and Metabolism 83 203-205

Foresta C, Galeazzi C, Bettella A, Marin P, Rossato M, Garolla A and Ferlin A (1999) Analysis of meiosis in intratesticular germ cells from subjects affected by classic Klinefelter's syndrome Journal of Clinical Endocrinology and Metabolism 84 3807-3810

Giltay JC, Kastrop PM, Tiemessen $\mathrm{CH}$, van Inzen WG, Scheres JM and 
Pearson PL (1999) Sperm analysis in a subfertile male with a $Y ; 16$ translocation, using four-color FISH Cytogenetics and Cell Genetics $\mathbf{8 4}$ $67-72$

*Guttenbach M, Engel W and Schmid M (1997a) Analysis of structural and numerical chromosome abnormalities in sperm of normal men and carriers of constitutional chromosome aberrations: a review Human Genetics 100 1-21

Guttenbach M, Michelmann HW, Hinney B, Engel W and Schmid M (1997b) Segregation of sex chromosomes into sperm nuclei in a man with 47,XXY Klinefelter's karyotype: a FISH analysis Human Genetics $99474-477$

Hassold T, Sherman S, Pettay D, Page D and Jacobs P (1991) XY chromosome nondisjunction in man is associated with diminished recombination in the pseudoautosomal region American Journal of Human Genetics 49 253-260

Honda H, Miharu N, Ohashi Y, Honda N, Hara T and Ohama K (1999) Analysis of segregation and aneuploidy in two reciprocal translocation carriers, $\mathrm{t}(3 ; 9)(\mathrm{q} 26.2 ; \mathrm{q} 32)$ and $\mathrm{t}(3 ; 9)(\mathrm{p} 25 ; \mathrm{q} 32)$, by triple-color fluorescence in situ hybridization Human Genetics 105 428-436

Honda H, Miharu N, Samura O, He H and Ohama K (2000) Meiotic segregation analysis of a 14;21 Robertsonian translocation carrier by fluorescence in situ hybridization Human Genetics 106 188-193

Hultén M (1970) Meiosis in XYY men Lancet 1 717-718

Hultén M and Pearson PL (1971) Fluorescent evidence for spermatocytes with two Y chromosomes in an XYY male Annals of Human Genetics 34 273-276

In't Veld PA, Weber RF, Los FJ, den Hollander N, Dhont M, Pieters MH and Van Hemel JO (1997) Two cases of Robertsonian translocations in oligozoospermic males and their consequences for pregnancies induced by intracytoplasmic sperm injection Human Reproduction 12 1642-1644

Jalbert P, Sele B and Jalbert H (1980) Reciprocal translocations: a way to predict the mode of imbalanced segregation by pachytene-diagram drawing Human Genetics 55 209-222

Johnson MD (1998) Genetic risks of intracytoplasmic sperm injection in the treatment of male infertility: recommendations for genetic counseling and screening Fertility and Sterility 70 397-411

Kruger TF, Acosta AA, Simmons KF, Swanson RJ, Matta JF and Oehninger S (1988) Predictive value of abnormal sperm morphology in in vitro fertilization Fertility and Sterility 49 112-117

Kruse R, Guttenbach M, Schartmann B, Schubert R, van der Ven H, Schmid $\mathbf{M}$ and Propping $\mathbf{P}$ (1998) Genetic counselling in a patient with $\mathrm{XXY/XXXY/XY}$ mosaic Klinefelter's syndrome: estimate of sex chromosome aberrations in sperm before intracytoplasmic sperm injection Fertility and Sterility $69432-485$

Lahdetie J, Saari N, Ajosenpaa-Saari M and Mykkanen J (1997) Incidence of aneuploid spermatozoa among infertile men studied by multicolor fluorescence in situ hybridization American Journal of Medical Genetics 71 115-121

Lee JD, Kamiguchi Y and Yanagimachi R (1996) Analysis of chromosome constitution of human spermatozoa with normal and aberrant head morphologies after injection into mouse oocytes Human Reproduction 11 1942-1946

Li P and Hoshiai H (1998) Detection of numerical chromosome abnormalities in human spermatozoa by three-color fluorescence in situ hybridization Journal of Obstetrics and Gynaecological Research 24 385-392

Liebaers I, Bonduelle M, Van Assche E, Devroey P and Van Steirteghem A (1995) Sex chromosome abnormalities after intracytoplasmic sperm injection Lancet 3461095

Lim AS, Fong $\mathbf{Y}$ and Yu SL (1999) Estimates of sperm sex chromosome disomy and diploidy rates in a 47,XXY/46, XY mosaic Klinefelter patient Human Genetics 104 405-409

McInnes B, Rademaker A, Greene CA, Ko E, Barclay L and Martin R (1998) Abnormalities for chromosomes 13 and 21 detected in spermatozoa from infertile men Human Reproduction 13 2787-2790

Martin RH (1984) Analysis of human sperm chromosome complements from a male heterozygous for a reciprocal translocation t(11;22)(q23;q11) Clinical Genetics 25 357-361
Martin RH (1988) Cytogenetic analysis of sperm from a male heterozygous for a 13;14 Robertsonian translocation Human Genetics 80 357-361

Martin RH (1995) Sperm cell - genetic aspects. In Cambridge Reviews in Human Reproduction pp 104-121 Eds JG Grudzinskas et al. Cambridge University Press, Cambridge

Martin RH (1996) The risk of chromosomal abnormalities following ICSI Human Reproduction 11 924-925

Martin RH and Rademaker A (1988) The relationship between sperm chromosomal abnormalities and sperm morphology in humans Mutation Research 207 159-164

Martin RH and Spriggs EL (1995) Sperm chromosome complements in a man heterozygous for a reciprocal translocation $46, \mathrm{XY}, \mathrm{t}(9 ; 13)(\mathrm{q} 21.1 ; \mathrm{q} 21.2)$ and a review of the literature Clinical Genetics 47 42-46

Martin RH, Mclnnes B and Rademaker AW (1999) Analysis of aneuploidy for chromosomes 13,21, X, and $Y$ by multicolour fluoresence in situ hybridization (FISH) in a 47,XYY male Zygote 7 131-134

Martin R, Greene C, Rademaker A, Barclay L, Ko E and Chernos J (2000) Chromosome analysis of spermatozoa extracted from testes of men with non-obstructive azoospermia Human Reproduction 15 1121-1124

Martinez-Pasarell O, Vidal F, Colls P, Nogues C, Egozcue J and Templado C (1997) Sex chromosome aneuploidy in sperm-derived pronuclei, motile sperm and unselected sperm, scored by three-color FISH Cytogenetics and Cell Genetics 78 27-30

Martini E, von Bergh A, Coonen E, de Die-Smulders C, Hopman A, Ramaekers F and Geraedts J (1998) Detection of structural abnormalities in spermatozoa of a translocation carrier $\mathrm{t}(3 ; 11)(\mathrm{q} 27.3 ; \mathrm{q} 24.3)$ by triple FISH Human Genetics 102 157-165

Mercier S, Morel F, Roux C, Clavequin MC and Bresson JL (1996) Analysis of the sex chromosomal equipment in spermatozoa of a 47,XYY male using two-colour fluorescence in situ hybridization Molecular Human Reproduction 2 485-488

Mercier S, Morel F, Fellman F, Roux C and Bresson J (1998) Molecular analysis of the chromosomal equipment in spermatozoa of a $46, X Y$, $\mathrm{t}(7 ; 8)(\mathrm{q} 11.21$; cen) carrier by using fluorescence in situ hybridization Human Genetics 102 446-451

Meschede D, Louwen F, Eiben B and Horst J (1997) Intracytoplasmic sperm injection pregnancy with fetal trisomy $9 p$ resulting from a balanced paternal translocation Human Reproduction 12 1913-1914

Miharu N, Best RG and Young SR (1994) Numerical chromosome abnormalities in spermatozoa of fertile and infertile men detected by fluorescence in situ hybridization Human Genetics 93 502-506

Moosani N, Pattinson H, Carter M, Cox D, Rademaker A and Martin R (1995) Chromosomal analysis of sperm from men with idiopathic infertility using sperm karyotyping and fluorescence in situ hybridization Fertility and Sterility 64 811-817

Moosani N, Chernos J, Lowry RB, Martin RH and Rademaker A (1999) A $47, X X Y$ fetus resulting from ICSI in a man with an elevated frequency of 24,XY spermatozoa Human Reproduction 14 1137-1138

Morel F, Roux C and Bresson JL (2000) Segregation of sex chromosomes in spermatozoa of $46, X Y / 47, X X Y$ men by multicolour fluorescence in situ hybridization Molecular Human Reproduction 6 566-570

Nishikawa N, Murakami I, Ikuta K and Suzumori K (2000) Sex chromosomal analysis of spermatozoa from infertile men using fluorescence in situ hybridization Journal of Assisted Reproduction and Genetics 17 97-102

Ogawa S, Araki S, Araki Y, Ohno M and Sato I (2000) Chromosome analysis of human spermatozoa from an oligoasthenozoospermic carrier for a 13;14 Robertsonian translocation by their injection into mouse oocytes Human Reproduction 15 1136-1139

*Pang M, Hoegerman S, Cuticchia A, Moon S, Doncel G, Acosta A and Kearns W (1999) Detection of aneuploidy for chromosomes 4, 6, 7, 8, 9, $10,11,12,13,17,18,21, \mathrm{X}$ and $\mathrm{Y}$ by fluorescence in situ hybridization in spermatozoa from nine patients with oligoasthenoteratozoospermia undergoing intracytoplasmic sperm injection Human Reproduction 14 1266-1273

Pellestor F, Sele B and Jalbert H (1987) Chromosome analysis of spermatozoa from a male heterozygous for a 13;14 Robertsonian translocation Human Genetics 76 116-120

Pellestor F, Girardet A, Coignet L, Andreo B, Lefort G and Charlieu JP 
(1997) Cytogenetic analysis of meiotic segregation in sperm from two males heterozygous for reciprocal translocations using PRINS and humster techniques Cytogenetics and Cell Genetics 78 202-208

Pfeffer J, Pang M, Hoegerman S, Osgood C, Stacey M, Mayer J, Oehninger S and Kearns W (1999) Aneuploidy frequencies in semen fractions from ten oligoasthenoteratozoospermic patients donating sperm for intracytoplasmic sperm injection Fertility and Sterility 72 472-478

Reubinoff BE, Abeliovich D, Werner M, Schenker JG, Safran A and Lewin A (1998) A birth in non-mosaic Klinefelter's syndrome after testicular fine needle aspiration, intracytoplasmic sperm injection and preimplantation genetic diagnosis Human Reproduction 13 1887-1892

Rives N, Saint Clair A, Mazurier S, Sibert L, Simeon N, Joly G and Mace B (1999) Relationship between clinical phenotype, semen parameters and aneuploidy frequency in sperm nuclei of 50 infertile males Human Genetics 105 266-272

Rives N, Joly G, Machy A, Simeon N, Leclerc P and Mace B (2000) Assessment of sex chromosome aneuploidy in sperm nuclei from 47, XXY and $46, X Y / 47, X X Y$ males: comparison with fertile and infertile males with normal karyotype Molecular Human Reproduction 6 107-112

Ron-el R, Friedler S, Strassburger D, Komarovsky D, Schachter M and Raziel A (1999) Birth of a healthy neonate following the intracytoplasmic injection of testicular spermatozoa from a patient with Klinefelter's syndrome Human Reproduction 14 368-370

Ron-El R, Raziel A, Strassburger D, Schachter M, Bern O and Friedler S (2000a) Birth of healthy male twins after intracytoplasmic sperm injection of frozen-thawed testicular spermatozoa from a patient with nonmosaic Klinefelter syndrome Fertility and Sterility 74 832-833

Ron-El R, Strassburger D, Gelman-Kohan S, Friedler S, Raziel A and Appelman Z (2000b) A 47,XXY fetus conceived after ICSI of spermatozoa from a patient with non-mosaic Klinefelter's syndrome: case report Human Reproduction 15 1804-1806

Rousseaux S, Chevret E, Monteil M, Cozzi J, Pelletier R, Delafontaine D and Sele B (1995a) Sperm nuclei analysis of a Robertsonian t(14q;21q carrier, by FISH, using three plasmids and two YAC probes Human Genetics 96 655-660

Rousseaux S, Chevret E, Monteil M, Cozzi J, Pelletier R, Devillard F, Lespinasse J and Sele B (1995b) Meiotic segregation in males heterozygote for reciprocal translocations: analysis of sperm nuclei by two and three colour fluorescence in situ hybridization Cytogenetics and Cell Genetics 71 240-246

Savage AR, Petersen MB, Pettay D, Taft L, Allran K, Freeman SB, Karadima G, Avramopoulos D, Torfs C, Mikkelsen M, Hassold TJ and Sherman S (1998) Elucidating the mechanisms of paternal non-disjunction of chromosome 21 in humans Human Molecular Genetics 7 1221-1227

*Shi Q and Martin RH (2000a) Aneuploidy in human sperm: a review of the frequency and distribution of aneuploidy, effects of donor age and lifestyle factors Cytogenetics and Cell Genetics 90 219-226

*Shi Q and Martin RH (2000b) Multicolor fluorescence in situ hybridization analysis of meiotic chromosome segregation in a 47,XYY male and a review of the literature American Journal of Medical Genetics 93 40-46

Shi Q, Spriggs E, Field LL, Ko E, Barclay L and Martin RH (2001) Single sperm typing demonstrates that reduced recombination is associated with the production of aneuploid 24,XY human sperm American Journal of Medical Genetics 99 34-38

Spriggs EL and Martin RH (1994) Analysis of segregation in a human male reciprocal translocation carrier, $\mathrm{t}(1 ; 11)(\mathrm{p} 36.3 ; \mathrm{q} 13.1)$, by two-colour fluorescence in situ hybridization Molecular Reproduction and Development 38 247-250

Sundequist U and Hellstrom E (1969) Transmission of 47, XYY karyotype? Lancet 21367

Templado C, Vidal F, Navarro J, Marina S and Egozcue J (1984) Meiotic studies and synaptonemal complex analysis in two infertile males with a 13/14 balanced translocation Human Genetics 67 162-165

Thompson MW, McInnes RR and Willard HF (1986) Clinical cytogenetics: general principles and autosomal abnormalities. In Genetics in Medicine 5th Edn pp 201-229 Eds MW Thompson et al. WB Saunders, Toronto

Ushijima C, Kumasako Y, Kihaile PE, Hirotsuru K and Utsunomiya T (2000) Analysis of chromosomal abnormalities in human spermatozoa using multi-colour fluorescence in situ hybridization Human Reproduction 15 1107-1111

Van Assche E, Staessen C, Vegetti W, Bonduelle M, Vandervorst M, Van Steirteghem A and Liebaers I (1999) Preimplantation genetic diagnosis and sperm analysis by fluorescence in situ hybridization for the most common reciprocal translocation $\mathrm{t}(11 ; 22)$ Molecular Human Reproduction 5 682-690

Van Hummelen P, Manchester D, Lowe X and Wyrobek A (1997) Meiotic segregation, recombination, and gamete aneuploidy assessed in a $\mathrm{t}(1 ; 10)(\mathrm{p} 22.1 ; \mathrm{q} 22.3)$ reciprocal translocation carrier by three- and fourprobe multicolor FISH in sperm American Journal of Human Genetics $61651-659$

*Van Opstal D, Los FJ, Ramlakhan S, Van Hemel JO, Van Den Ouweland AM, Brandenburg H, Pieters MH, Verhoeff A, Vermeer MC, Dhont M and In't Veld PA (1997) Determination of the parent of origin in nine cases of prenatally detected chromosome aberrations found after intracytoplasmic sperm injection Human Reproduction 12 682-686

Vegetti W, Van Assche E, Frias A, Verheyen G, Bianchi MM, Bonduelle M, Liebaers I and Van Steirteghem A (2000) Correlation between semen parameters and sperm aneuploidy rates investigated by fluorescence in situ hybridization in infertile men Human Reproduction 15 351-365

Vidal F, Templado C, Navarro J, Marina S and Egozcue J (1982) Meiotic and synaptonemal complex studies in a 14/21 translocation carrier International Journal of Andrology 5 21-26

World Health Organization (1993) Laboratory Manual for the Examination of Human Semen and Semen-Cervical Mucus Interaction 3rd Edn. Springer-Verlag, Berlin

Zech H, Vanderzwalmen P, Prapas Y, Lejeune B, Duba E and Schoysman R (2000) Congenital malformations after intracytoplasmic injection of spermatids Human Reproduction 15 969-971

Zeyneloglu HB, Baltaci V, Ege S, Haberal A and Batioglu S (2000) Detection of chromosomal abnormalities by fluorescent in-situ hybridization in immotile viable spermatozoa determined by hypo-osmotic sperm swelling test Human Reproduction 15 853-856 